Cumhuriyet International Journal of Education-CIJE

e-ISSN: 2147-1606

Vol 5(4), 2016, 55 - 71

\title{
Mathematical Modeling Processes of Mathematics Teacher Candidates: The Example of Tortoise Paradox ${ }^{1}$
}

\author{
Murat DURAN², Muhammet DORUK ${ }^{3}$, Abdullah KAPLAN ${ }^{4}$
}

\author{
Summary
}

\section{INTRODUCTION}

Today, expectations in mathematics education have changed with the development of science and technology (Biber \& Baser, 2012). Varying expectations in this area, it is intended to train individuals who can solve routine and non-routine problems, use math in everyday life, access to the good judgment and think creatively (Ciltas \& Yilmaz, 2013; Dossey \& McCrone, 2007). For this purpose, National Council of Teachers of Mathematics (NCTM) has stated that the students studying in pre-school and high school period should use the mathematics models in their problem solving to understand mathematical relationships (NCTM, 2000). Similarly, the Ministry of National Education (MEB) in the Republic of Turkey revised the secondary school mathematics curriculum in 2013 and aimed to be configured the basic mathematical skills based on real life problems by individuals. In the same curriculum, it was referred to the preparation of studying environment provided to solve problems through modeling for the students (MEB, 2013). When considering the difficulties faced by individuals in the process of establishing the relationship between the mathematical world with the real World, the mathematical modeling is an important tool in the context of overarching the mathematical concepts to every life.

In the literature, the mathematical modeling is defined as a complex and iterative process that involves the transformation between real-life and mathematical world (Borromeo-Ferri, 2006). In said process, five steps of mathematical modeling are understanding of the real problem and creating a model based on reality, creating a mathematical model of the real model, solving the created mathematical model, interpretation the mathematical results and verification the solution (Blum \& Kaiser, 2007; cited in Maaß, 2006). Large task falls to the teachers at the gaining process to modeling adequacy of individuals and integrating process to lessons of mathematical modeling considered an important component in mathematics courses (Tekin Dede \& Yilmaz, 2013). Therefore, the competence of mathematical modeling need to be gained mathematics teacher candidates at universities in the future (Bukova Guzel \& Ugurel, 2010; Borromeo-Ferri \& Blum, 2010). It is important for the mathematics teacher candidates to determine the proficiency levels of modeling on basic mathematical topics before gaining the qualifications. Thus, the purpose of the study is to determine the current models for geometric series produced by the middleschool mathematics teacher candidates and classify these models.

\section{METHODS}

A case study of the qualitative research method was adopted in this research. The case study was preferred in this research because the examination desire in-depth of the produced models in the process of problem solving known as the current state. This research was conducted with final year mathematics teacher candidates studying elementary mathematics

\footnotetext{
${ }^{1}$ A part of this study was published as a short summary in the $3^{\text {rd }}$ International Eurasian Educational Research Congress (Muğla Sıtkı Koçman University, 1-3 June 2016, Muğla, Turkey).

2 PhD. Student, Ataturk University, Institute of Educational Sciences, denizyildizi2805@hotmail.com

${ }^{3}$ Res. Asst. Dr., Hakkari University, Education Faculty, mdoruk20@gmail.com

4Prof. Dr., Ataturk University, Kazım Karabekir Education Faculty, akaplan@atauni.edu.tr
} 
$(\mathrm{n}=41)$. This research applied at the state university in the large-scale city of Eastern Anatolia Region of Turkey was carried out in the fall semester of 2013-2014 academic years. When the sample of the research was determining, the criterion sampling among the purposeful sampling method was used. The sampling criteria of the research is to possess the necessary knowledge and skills in mathematical modeling and take the course Analysis III taught the series topic. The real names of the teacher candidates were hidden and the code names were given to them in the research. Data collection tool of the research is the paradox named "Tortoise Paradox" in the literature posed by the Greek Mathematician Zeno. The reason of the designation for the paradox is intended to be a mathematical model of the problem in paradox. An expert explained an opinion whether the paradox was used in modeling or not. At the end of the views of the expert, the paradox was rearranged the cover feature including the steps of the loop of modeling. The answers given for the problem in paradox by teacher candidates were received as written at one lesson time. The researchers didn't make any intervention to the teacher candidates during the solution of the problem for the paradox. The answers obtained from the detailed modeling examples of teacher candidates were examined with the descriptive analysis. The forms of representation used by teacher candidates in the process of modeling were examined under verbal, algebraic, formal, graphical and table topics by the researchers.

\section{RESULTS AND CONCLUSIONS}

According to the results obtained from the research, it is seemed that middle school mathematics teacher candidates have difficulty in drawing appropriate mathematical model for tortoise paradox. Also, it has been found that these difficulties have increased even more. Teacher candidates showed inadequate approach on the steps named "interpretation the results in a real situation" and "solution verification" among the modeling steps. Also, teacher candidates have used the most algebraic and visual models in the modeling process. But, it has been determined that very few of the mathematical models produced by teacher candidates are compatible with the logic of the problem. This result obtained from the study were consistent with the results of the study conducted by Ozaltun, Hidiroglu, Kula and Bukova Guzel (2013). They said that even if reaching mathematical model was important in the process of modeling, visual representations were also needed as well as the algebraic representation of the model topic in their study. According to the results of the research, it is suggested to be applied problems for the construction of the mathematical models with the help of the multiple representations and rearranged the learning environments considering this situation by teacher candidates. 